\title{
TRADICIÓN CLÁSICA EN LAS GUERRAS DE CHILE
}

\author{
THE CLASSICAL TRADITION IN LAS GUERRAS DE CHILE
}

\section{MARÍA GABRIELA HUIDOBRO SALAZAR ${ }^{1}$}

\section{RESUMEN}

El poema épico Las guerras de Chile ha sido poco estudiado y por lo general se le ha abordado como testimonio histórico de la Guerra de Arauco. Sin embargo, posee también un valor literario y cultural, debido a la influencia de la tradición clásica sobre él, lo que hasta ahora no ha sido analizado. En este artículo se propone la lectura de un pasaje del poema a la luz de algunos tópicos de la tradición épica clásica, con el fin de revalorizar la obra como testimonio no sólo de hechos históricos, sino también de la perspectiva cultural con que se los representó.

Palabras clave: Las guerras de Chile, poesía épica, tradición clásica, tópicos épicos.

\section{ABSTRACT}

Las guerras de Chile is an epic poem that has been studied -in general- only as an historical testimony of the Arauco War. Nevertheless, due to its being influenced by the classical tradition, this poem also has a literary and cultural value which has not been analyzed. The aim of this paper is to read a passage of the poem focusing on some topics of the epic tradition in order to consider these verses not only as a testimony of historical facts, but also to value the cultural perspective in which those facts are represented.

Keywords: Las guerras de Chile, epic poetry, classical tradition, epic topics.

Recibido: 07.06.10. Aceptado: 11.01.11.

${ }^{1}$ Doctora @ en Historia Universidad Andrés Bello. Santiago, Chile. E-mail: mhuidobro@unab.cl 
OMO un manuscrito anónimo y sólo con el título "Canto I" en su primera página se encontraba el poema Las guerras de Chile, hasta ser hallado en el siglo XIX por Diego Barros Arana en la Biblioteca Nacional de Madrid, y publicado por José Toribio Medina el año $1888^{2}$.

Aunque suele atribuirse a Juan de Mendoza Monteagudo, la única certeza que se tiene a través de los datos ofrecidos por el mismo poeta en el canto V de su obra, es que éste fue un soldado que el año 1599, y tras haber participado en otros hechos de la conquista en América, se embarcó con las tropas del gobernador Francisco de Quiñones para combatir el levantamiento de los indígenas de Arauco (O’Ryan, 1898) ${ }^{3}$.

Las guerras de Chile está compuesto por once cantos, que comienzan, tal como La Araucana, con una descripción de Chile y de su gente, y con un breve resumen sobre el conflicto entre araucanos y españoles, desde los tiempos de Valdivia hasta la muerte del gobernador Loyola en 1598. Desde tal acontecimiento y a partir del canto III, la narración trata acerca de los asedios a los hispanos por parte de los araucanos, y el viaje y llegada de Francisco de Quiñones en auxilio de los colonos. La obra culmina con la narración de la llegada de unas naves holandesas a las costas de Castro y con el relato de los marinos, comandados por Simón de Cordes, acerca de las aventuras que los habían conducido hasta las playas chilenas.

Por su naturaleza testimonial, el poema ha sido apreciado especialmente por su valor histórico, ya que pretendería una descripción objetiva de la experiencia personal del autor en Chile. Sin embargo, los elementos literarios y las digresiones insertas en el poema han quedado al margen de esta valoración, y aunque se las reconoce como partes necesarias de un poema épico, no han merecido la atención que en este caso pretendemos otorgarle.

Si bien el autor revela una intención que es ante todo histórica, su creatividad poética comienza a asomarse en el transcurso de la narración y adquiere forma con el estilo literario de la época, que Ercilla había consolidado para las epopeyas que cantaron los hechos de Arauco: el de la imitación y evocación de los modelos clásicos.

José Toribio Medina, quien comentaba el valor histórico del poema, reconocía que las reflexiones morales y los personajes alegóricos insertos en él, aunque lo alejaban de la realidad, no la deformaban, sino que servían

${ }^{2}$ La edición fue publicada bajo el nombre de Juan de Mendoza Monteagudo y se antecede de un prólogo escrito por Medina, que justifica la vinculación de dicho personaje con la autoría del poema.

${ }^{3}$ Este periodo es también relatado en versos por Diego Arias de Saavedra en el poema Purén indómito (1603). 
para su ornamentación. No obstante, parece atribuir estos elementos a la individualidad del autor, pues señalaba que "se encuentran también en el poema de Mendoza algunos de sus rasgos personales, como impregnados de su espíritu, de sus tendencias e inclinaciones" (1878).

En el prólogo a la edición de ese poema, Medina reforzaba su tesis sobre la singularidad de la poetización del testimonio, afirmando: "Cualquiera que sea el mérito literario de Las guerras de Chile, no debemos olvidar al juzgar el libro del poeta chileno, que sus versos se amoldan siempre a la verdad de los sucesos que narra, que vivió y escribió en el más pobre y apartado rincón de la tierra, sin modelos, sin estímulo y sin pretensiones" (1888).

Sin embargo, su conjetura nos parece cuestionable cuando advertimos, en los versos del poema, la mención de figuras de la Antigüedad -mitológicas e históricas- y cuando algunos de sus pasajes nos evocan escenas y formas que bien podríamos reconocer en la tradición épica que precede a esta obra.

El autor de Las guerras de Chile nos parece claramente influido por los modelos grecorromanos, no sólo por un apego al estilo literario que imperaba en su época, sino también porque estos modelos, en su calidad de clásicos, parecen servirle para la comprensión, explicación y representación de los hechos que vivió.

De este modo, en el poema no sólo podemos leer acerca de ciertos hitos de la historia de Chile, sino también sobre aventuras y hazañas que responden a temáticas propias del género y de la tradición en los que la obra se inscribe. En este sentido, en Las guerras de Chile puede leerse la narración de algunos acontecimientos de la Guerra de Arauco, organizados y expresados bajo la inspiración de los modelos clásicos, y específicamente de ciertos tópicos, perífrasis, símiles y metonimias, que permiten al autor no sólo ornar sus versos con el estilo de la época, sino también cargarlos de sentido, otorgando categoría épica a tales hechos.

A la luz de esta perspectiva, hemos escogido un pasaje que se inspira en dos tópicos de la tradición épica clásica -la tempestad y el viaje- para dar forma, valor y sentido a su relato. Se trata del viaje por mar de Francisco de Quiñones y sus tropas hacia Chile el año 1599, asunto que ocupa al poeta entre los cantos VI y VII de su obra.

\section{EL VIAJE “ODISEICO” DE JUAN FERNÁNDEZ}

El canto VI de Las guerras de Chile se inicia con la descripción de las naves comandadas por Quiñones, zarpando desde el Callao con dirección al sur: 


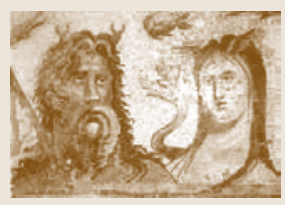

Océano y Tetis

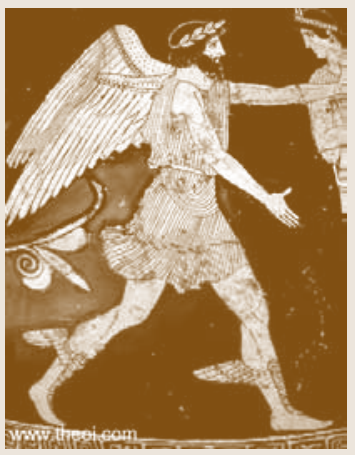

Bóreas
Dando a la inmensa Tetis las costillas, Se dejan el Callao a barlovento: A la casa del Toro el sol llegaba, Que ya atrás la del Aries se dejaba.

$$
(\mathrm{V}, 1,4-8)^{4}
$$

La primera octava nos ofrece ya una metonimia, que hace de Tetis el mar y que nos otorga un antecedente de los conocimientos astronómicos que el poeta posee, que desplegará especialmente en los versos que cantan asuntos marítimos. Las naves han zarpado a comienzos del otoño y el poeta se encarga de advertir al lector las dificultades que tal estación supone para la navegación por los mares de Chile 5 . Para ello se sirve de la personificación mitológica de los vientos -aquéllos sometidos a Eolo- y de los astros, nombrando a Arcturus, aquel que se muestra en el tercer mes del invierno ${ }^{6}$ :

Tanta violencia tiene en aquel polo

El invérnico Bóreas de ordinario

Que por aquellas costas anda solo

Repugnante, fugaz y temerario:

No puede reprimir su furia Eolo,

Que Arturo, su vecino y su contrario,

La secreta caverna viendo abierta

Le da por la bocina franca puerta.

No obstante, la octava siguiente sirve al poeta para, al estilo de Ariosto, disculparse y dejar el tema que había iniciado, trasladando la acción nuevamente a Arauco. Sólo el canto VII retomará la navegación de Quiñones y desarrollará el tema del viaje y de la tempestad, que ya había anunciado con los nombres de Bóreas y de Arturo en el canto anterior.

\footnotetext{
${ }^{4}$ Los versos han sido citados de la edición de Medina, pero en ésta no se hallan numerados, por lo que la numeración ha sido realizada para el presente análisis en forma personal y corresponde a las octavas de cada canto y a los versos de cada una de ellas. Las citas han sido confrontadas, además, con el manuscrito original, que nos ha llevado en algunas oportunidades a diferir de la edición referida.

${ }^{5}$ Diego Barros Arana concreta el testimonio del poeta, con afirmaciones que resultan más específicas y objetivas: “Don Francisco de Quiñones logró al fin reunir dos buques, y en ellos zarpó del Callao el 12 de mayo, trayendo por piloto mayor a don Juan de Cárdenas y Añasco, marino experimentado en esta navegación. Comenzaba entonces la estación de los vientos del norte, que si bien facilitan y abrevian esta navegación, suelen convertirse en tempestades deshechas" (1884).

${ }^{6}$ Hes., Op., 564-567; Arat., Phaen., 95 y 744-746, donde se señala que una tormenta puede pronosticarse atendiendo a esta estrella.
} 
Arando la ancha espalda a Tetis fría (VII, 20, 2), las naves habían avanzado hacia el sur con la fuerza de los vientos propios de esos meses del año. Pero empujados por la fuerza del Noto (VII, 20, 7), se vieron obligados a cambiar tres grados su rumbo, buscando del esperado Aquilas más liviano (VII, 21, 4) una navegación más controlada. Las explicaciones de la navegación se enriquecen así de los nombres mitológicos de los vientos, que nos invitan a pensar en su travesía como una de aquéllas de la tradición épica.

Sin embargo, la aventura que el poeta comienza a relatar no es la de las naves en las que él mismo habría viajado, sino la de un navegante que antes que ellos había pasado por los mismos derroteros, arribando a las islas que en ese momento los hombres de Quiñones avistaban. Así, tras señalar que habían hallado una ruta más calma, el poeta afirma que por la banda del este se les comenzaba a mostrar el archipiélago de Juan Fernández, que precisamente llevaba el nombre de ese aventurero.

Éste es el motivo que introduce al poeta a referir la travesía de Juan Fernández y los avatares que en ella padeció, episodio que rememora las odiseas de los navegantes de la Antigüedad. Se trata de un excurso que ocupa prácticamente todo el canto VII y que parece insertarse, a primera vista, por esa motivación literaria de hacerse parte de la tradición, siguiendo los códigos y modelos de la epopeya clásica.

La figura de Juan Fernández se nos presenta desde un comienzo como el protagonista de una odisea:

Él fue quien, cual Demócrito o Teseo, Tentando varios temples de contino, Por tierra anduvo más que Tolomeo, $\mathrm{Y}$ en mar fue un Magallanes peregrino; El arte ejercitó de Salganeo; Piloto siempre fue y piloto vino A serlo en estos mares cuando inciertos Los hombres navegaban por los puertos.

(VII, 24)

\footnotetext{
${ }^{7}$ El testimonio de Estrabón nos explica quién fue Salganeo y qué sentido puede tener su incorporación en esta octava. En referencia a un lugar del mismo nombre, Estrabón afirma que proviene de "Salganeo, un beocio que fue enterrado allí, el hombre que guiaba a los persas cuando ellos se adentraron en este estrecho procedentes del golfo Malíaco. Dicen que, antes de tocar el Euripo, fue condenado a muerte por el almirante Megábatas, por pensar que era un granuja, al creer que introducía la flota engañosamente en un estrecho de mar sin salida; y que cuando el bárbaro se dio cuenta de su error, se arrepintió y consideró merecedor de un entierro al que había muerto sin ser culpable" (Str., IX, 2, 9). Salganeo era, entonces, un avezado piloto, tal como pretendía serlo Juan Fernández.
}

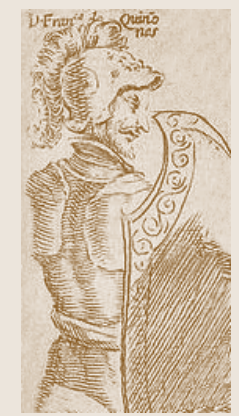

F. de Quiñones 
Que muestra el viejo amante de Oritía ${ }^{9}$

Cuan malo es dejar un lecho blando

(VII, 28, 3-4)

Tal como en las Argonáuticas de Valerio Flaco, es Bóreas -aunque con una participación menos literaria y en una referencia más histórica- quien inicia la tempestad. Los vientos se desatan y al navegante se le hace sumamente difícil mantener su rumbo (VII, 30-33). Es ocasión de echar mano, nuevamente, a la tradición clásica para evocar figuras y pasajes que bien sirven para representar ese momento, en especial aquel de $O d$., $\mathrm{X}, 45$ y ss., cuando los hombres de Ulises, desoyendo las advertencias de Eolo, liberan a los vientos:

Contino dando vueltas como Apolo

Y siempre como Clicie el sol mirando ${ }^{10}$,

Se vuelve de la popa al astral polo ${ }^{11}$

Al viento como a siervo amenazando.

No le puede regir, que no es Eolo,

Mas vese como Ulises ir tratando,

Que el viento ya del odre desatado

A su pesar le lleva derrotado.

(VII, 34)

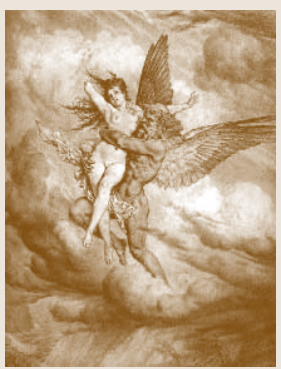

Bóreas raptando a Oritía

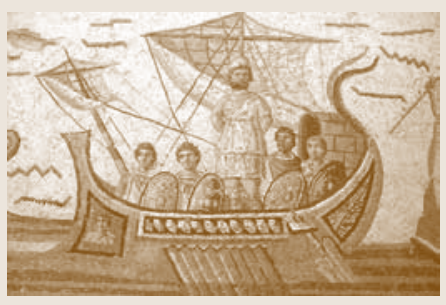

Ulises

${ }^{9}$ La edición de Medina presenta el verso VII, 28, 3 en los siguientes términos: "que muestra el viejo amante de Ontia”. Nuestra revisión del manuscrito nos permite suponer, en cambio, que el verso menciona a Oritía, la hija de Erecteo y de Praxitea de Atenas, de quien Bóreas se enamoró (Ov., Met., VI, 683 y ss.; Apollod., III, 15, 1; Apollon. Rhod., I, 215 y ss.). Cuando se habla del "amante de Oritía", se habla del viento del norte, que aunque más fuerte, suele provocar tormentas, tal como lo recordaba Barros Arana (1884) aludiendo a los mares de Chile. Y así, la octava que sigue continúa una descripción del mismo viento:

Por la contraria parte fin derecho

Del contrapuesto punto del altura

Sopla el terrestre vaho tan derecho

Cuanto para engolfárselo procura.

(VII, 29, 1-4)

${ }^{10}$ La edición de Medina reemplaza con puntos suspensivos el nombre de Clicie o Clitie. Nos parece que la presencia de esta figura tiene sentido considerando que se sigue de la mención de Apolo, a quien ella amó y al que, despreciada por éste, admiró sentada en la Tierra, con el rostro vuelto al sol, hasta su muerte (Ov., Met., IV, 256 y ss.).

${ }^{11}$ Nuevamente diferimos con la edición de 1888, que en este verso refiere al "otro polo", pero que en el manuscrito nos parece leer "astral polo", sobre todo considerando que hasta el verso anterior se ha sugerido el nombre de Apolo aludiendo al sol. 
Tres veces por el tético ancho lecho (VII, 36, 1) se asomó el sol mientras Juan Fernández mantenía su lucha con la tempestad, hasta que en la cuarta jornada, el viento decide dar una solución extraordinaria a este conflicto: envolviendo la nave en una densa neblina, la eleva al cielo y la hace navegar por los aires. Se introduce con ello un elemento mágico y se abre así un pasaje de ficción que, lejos de tener sustento histórico, parece incorporarse con un propósito literario y moral.

Según el poeta, Juan Fernández había iniciado su viaje movido por la codicia y había desafiado a Bóreas soberbiamente. Al elevarse por los aires, el navegante tendrá entonces visiones tenebrosas, aunque finalmente no logren hacerlo desistir de su propósito. Palinuro, el piloto de Eneas que había caído al mar rendido por el Sueño, comienza a dirigir su nave (VII, 39, 2). Le siguen algunos versos más adelante otros espectros infernales, que parecen provenir, de todos modos, del Hades antes que del infierno cristiano:

Mostrando bien que vienen de Cocito, Las cárceles eternas quebrantando, Con son de hueco estrépito, maldito, Entre borrasca rápida cursando.

(VII, 42, 1-4)

La confusión se apodera del relato: estas almas perturban y cuestionan el rumbo del piloto, quien intenta obstinadamente dirigir a estos extraños marineros (VII, 39-50). El desenlace resulta igualmente confuso. Cansado ya el tropel luciferino (VII, 50,1), dice el poeta, parece haber abandonado a Juan Fernández, pero este motivo da pie para introducir a continuación el relato de una segunda tempestad, dejando atrás las aventuras de este intrépido marinero, cuyo sentido se completa con la lectura de este segundo episodio.

\section{LA ÉPICA TEMPESTAD CONTRA FRANCISCO DE QUIÑONES}

"La tempestad es un topos de la epopeya", afirma Vicente Cristóbal (1988) y como tal, podemos leerla en los versos de Las guerras de Chile, en el episodio protagonizado por Juan Fernández, así como en el que encabezará Francisco de Quiñones.

Sin embargo, aun tratándose de un tópico, la tempestad padecida por Quiñones está lejos de ser sólo ficción literaria. Se trata de un aconteci- 
miento histórico ${ }^{12}$, pero relatado en el poema con los códigos dictados por la tradición clásica. Homero, Nevio, Virgilio y Lucano, entre otros, sentaron las formas narrativas que en adelante imitarían los poetas épicos, incluso en tiempos modernos ${ }^{13}$. Ercilla y Oña, para el caso de los poemas sobre Arauco, continuaron esta tradición, y en Las guerras de Chile pretendemos ver así una huella más del mismo topos.

Francisco de Quiñones se dirigía a Chile con la misión de pacificarlo y de imponer el orden cristiano. ¿Qué motivos podría haber para que una tormenta sacudiera a estos españoles de noble causa? El poeta parece hallar la respuesta en la historia de Juan Fernández, cuyo excurso sirve para dar sentido a la historia que pretendía relatar y cuyas causas no eran sencillas de explicar.

La odisea de Juan Fernández parece explicarse así por un doble motivo: el de hallar razón de los padecimientos de la noble flota de Quiñones y el de ornar el relato con las formas clásicas de la epopeya. Las dos respuestas no nos parecen excluyentes, aunque al mismo tiempo sean ambas autosuficientes. Por una parte, el poeta intenta explicar cómo un buen cristiano sufre esta tempestad que históricamente se $\mathrm{dio}^{14}$. Sin embargo, podría haber bastado al poeta colocar el antecedente de la naturaleza climática de los mares de Chile y aun así, opta por cargar su descripción de elementos mitológicos y literarios. He aquí el peso de la tradición, que da fuerza al relato con figuras que simbólicamente lo cargan de sentido.

El desenlace de la travesía de Juan Fernández había quedado en suspenso, permitiendo así que el poeta aluda nuevamente a los vientos de Eolo. Esta vez, sin embargo, evoca la versión virgiliana de las cavernas, aunque sigue al mismo tiempo el argumento de las almas infernales:

\footnotetext{
${ }^{12}$ Una carta de Francisco de Quiñones dirigida a Su Majestad, con fecha 15 de julio de 1599, relata su viaje a Chile y los primeros sucesos de su llegada. En ella, el gobernador da cuenta de la tempestad que sacudió a sus naves y las dificultades que ello significó para su arribo al sur (Medina, 1902).

${ }^{13}$ El artículo de Vicente Cristóbal (1988) da cuenta detalladamente de la influencia de los clásicos en la incorporación y descripción épica de las tempestades en las epopeyas antiguas y modernas.

${ }^{14}$ Más adelante, el poeta describirá otra tormenta, este vez en Arauco, pero los únicos que sufrirán los avatares de ella serán los bárbaros (X, 89 y ss.). A los cristianos, en cambio, la lluvia los beneficiará.
} 
No sé si el viento indómito, violento,

De sus negras cavernas aventado,

No quiso la verdad mostrar del cuento

Con otro semejante confirmado,

O si el tropel maldito del tormento

De la de Juan Fernández despechado,

Quiso con removida furia nueva

Hacer en nuestras naos la propia prueba.

(VII, 51)

La octava 56 evoca, aunque indirectamente, los versos de Met, XI, 483 y ss., cuando los navegantes de Alcíone apenas oían las instrucciones para controlar la nave y aun así intentaban espontáneamente mantenerla a flote. Así se defendían también los hombres de Quiñones:

Unos corriendo al árbol de la escota,

"Larga la driza", dicen a porfía,

Otros, picos y la antena ven ya rota,

Otros, no venga, no, de Romanía,

Otros, bota el timón en rauda bota,

Y otros vira y corramos popa vía.

A todos se probaba, a todo se iba,

Mas no se amaina, corre, ni se arriba.

(VII, 56)

No era ya, solamente, el viento del norte. El Noto reventaba las velas (VII, 58, 7) y paulatinamente parecían converger en las naves de Quiñones las fuerzas de todos los vientos. Cuatro montes de aguas se forman a partir de ellas ${ }^{15}$, figura recurrente para este topos literario (insequitur cumulo praeruptus aquae mons, Aen. I, 105) y desde su mitológica caverna, los vientos van a dar todos a la vez sobre el mismo punto:

Aquesto de natura fue un exceso, Que sus espresas órdenes quebrantando,

Viéndolos en su cárcel descontentos,

La Furia redobló a los cuatro vientos.

$\mathrm{Y}$ conociendo a un punto su potencia

${ }^{15}$ Una imagen similar se lee algunos versos más adelante: "el mar en cordilleras ondeando" (VII, 65, 3). 
Los dos más resolutos e injuriados

De Júpiter simulan la sentencia,

Rompiendo la espelunca y los candados;

Mas viendo su terrible inobidiencia,

Conoce que a vengarse van airados,

Y pronto el prevenido rey severo

Soltó los otros dos también lijero.

(VII, 62, 5 y ss.)

Hay en estos versos ecos de Virgilio (Aen, I, 81 y ss.) y de Ovidio (Met., I, 263 y ss.). El poeta evoca a la figura de Júpiter y el control que debía tener sobre los diversos vientos de Eolo. Y a ellos se suma la mención de Neptuno, cuyos peligros también vienen todos a reunirse alrededor de la nave (VII, $66,7-8)$.

Sin embargo, los vientos sólo simulaban haber seguido las órdenes de Júpiter. Éste, en cambio, sólo interviene cuando advierte el caos desatado por los súbditos de Eolo. Pero se trata, al mismo tiempo, de una alusión mitológica que quiere referir finalmente a Dios, quien reemplaza de este modo al señor del Olimpo.

Por acojida el golfo, el puerto ausente,

Iba por trabucar a cada lado,

Cuando del alto Olimpo, el Gran Supremo

La cuita de los suyos vio y estremo.

$\mathrm{Y}$ al punto en su favor, propicio y tierno,

Su eterna voluntad desinclinando,

Un trueno de sonido salió eterno

Los turbios horizontes atronando:

Tembló la tierra, el mar, tembló el infierno,

Y todo su querer ratificando

Dejando los divisos elementos

Perdieron su furor los cuatro vientos.

(VII, 67, 5 y ss.)

Hay en estos versos una simbiosis entre Dios y los atributos de Júpiter y así, entre las creencias del poeta y sus modelos literarios: es Dios benefactor y justo, pero al mismo tiempo Júpiter atronador y señor de los vientos.

Finalmente, una de las dos naves que habían partido del Callao logra salvarse de esta tempestad, y quizás evocando la ayuda de las divinidades marinas (Aen, 144 y Val. Fl., 651 y ss.), Neptuno les deja el paso llano (VII, $69,7)$ para que ésta arribe a las costas de Talcahuano.

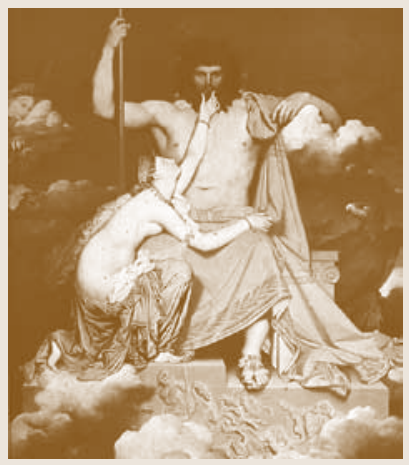

Júpiter 


\section{LA TRADICIÓN CLÁSICA EN LAS GUERRAS DE CHILE}

Si bien una lectura interesada en el aporte histórico puede rescatar el valor de Las guerras de Chile por los datos que ofrece para el conocimiento del periodo que relata, una lectura que atienda también a sus elementos literarios puede ampliar aun más esa valoración. No solamente por la variedad y la riqueza de la influencia de la tradición clásica que puede constatarse en sus versos -los analizados constituyen sólo un ejemplo-, sino también por el sentido de ésta.

Aun cuando la verificación de esta influencia puede permitirnos, en primera instancia, realizar una valoración filológica de la calidad de la obra o del nivel cultural de su autor, la presencia de los clásicos nos amplía también la valía de este poema desde una perspectiva histórica. En este sentido, en Las guerras de Chile no nos parece ver sólo la mención de personajes de la antigüedad o la alusión a figuras mitológicas y pasajes épicos simplemente por continuar los patrones literarios de la época. Antes bien, el autor parece sacar partido de ellos para configurar también la ideología que inspira sus cantos.

En los pasajes analizados no parece haber tanto digresiones cuanto alegorías. La tempestad de Juan Fernández interpreta los motivos de la tormenta que sacudió a las naves de Quiñones, logrando así -además de insertar el poema en la tradición literaria de los clásicos- ofrecer una explicación literaria y religiosa frente a los hechos históricos. Y la salvación de la flota española es también obra de la Divinidad, que no sólo se explica, en este caso, mediante un argumento teológico, sino que éste se conjuga con el imaginario de la tradición épica que magnifica y universaliza lo acontecido.

El mundo histórico del poeta parece inspirar su perspectiva épica y los clásicos le sirvieron para representarlo. Los últimos años del siglo XVI fueron especialmente dramáticos en Chile, pero tales circunstancias son las que precisamente se prestan para las hazañas, para los ejemplos de valor y de virtud, que el poeta bien pudo haber protagonizado o testimoniado.

Son motivos épicos que bien pudieron inspirar la perspectiva de este soldado que se volcó a los clásicos para dar forma, grandeza o sentido a sus experiencias. En sus versos advertimos entonces una intención por pasar a formar parte de la tradición literaria que lo precedía y por insertar los acontecimientos que vivió en el registro de las grandes proezas épicas de la historia. Pero también se asoma su inquietud por dar explicación de sus vivencias, la que se nutre y se afirma en las figuras e historias del pasado, 
esas que, en su condición de clásicas, adquieren, en cada autor y lector, un valor siempre renovado.

\section{REFERENCIAS}

Barros Arana, Diego. 1884. Historia general de Chile. Santiago de Chile: Imprenta Cervantes.

Cristóbal, Vicente. 1988. "Tempestades épicas”, CIF, XIV, 125-148.

Medina, José Toribio. 1878. Historia de la literatura colonial de Chile. Santiago de Chile: Imprenta Librería del Mercurio.

Medina, José Toribio. 1888. "Prólogo del editor", en Mendoza Monteagudo, Juan de, Las guerras de Chile. Santiago de Chile: Imprenta Ercilla.

Medina, José Toribio. 1902. Colección de Documentos Inéditos para la Historia de Chile, Segunda Serie. Santiago de Chile: Fondo Histórico y Bibliográfico J. T. Medina (reimpr. 1961).

Mendoza Monteagudo, Juan de. 1888. Las guerras de Chile. Santiago de Chile: Editorial Ercilla.

O’Ryan, Juan Enrique. 1898. Don Juan de Mendoza Monteagudo. Estudio crítico. Valparaíso: Imprenta de la Patria.

Valero Juan, Eva María. 2008. "Por el camino de la mar, el viaje hacia el ideal de Alonso de Ercilla”, en Atenea 498, 11-31.

Vicuña Mackenna, Benjamín. 1883. Juan Fernández: historia verdadera de la isla de Robinson Crusoe. Santiago de Chile: Ed. de Rafael Jover. 